\title{
A Cross-Sectional Population-Based Survey of Trachoma among Migrant School Aged Children in Shanghai, China
}

\author{
Wenwen Xue, ${ }^{1,2}$ Lina Lu, ${ }^{1}$ Jianfeng Zhu, ${ }^{1}$ Xiangui He, ${ }^{1}$ Jiangnan He, ${ }^{1}$ \\ Rong Zhao, ${ }^{1}$ and Haidong Zou ${ }^{1,2}$ \\ ${ }^{1}$ Shanghai Eye Disease Prevention \& Treatment Centre, Shanghai 200040, China \\ ${ }^{2}$ Shanghai General Hospital, Shanghai Jiao Tong University School of Medicine, Shanghai 200080, China \\ Correspondence should be addressed to Haidong Zou; zouhaidong@hotmail.com
}

Received 12 June 2016; Revised 28 July 2016; Accepted 28 July 2016

Academic Editor: Vishal Jhanji

Copyright (C) 2016 Wenwen Xue et al. This is an open access article distributed under the Creative Commons Attribution License, which permits unrestricted use, distribution, and reproduction in any medium, provided the original work is properly cited.

We investigated the prevalence of clinical trachoma in 154,265 children aged 6 to 16 years in 206 Shanghai migrant schools. Clean water availability in school, each child's facial cleanliness, eyelids, corneas, and the presenting distance visual acuities were examined. Trachoma was clinically diagnosed in accordance with the World Health Organization simplified classification. Eyes diagnosed with trachoma were swabbed to test for ocular Chlamydia trachomatis infections (OCTI) with a rapid latex immunochromatographic test. Among 153,977 students, no blindness was found related to trachoma. Trachoma was diagnosed in 8029 children (5.2\%). In 87 schools clinical trachoma prevalence was higher than 5\%. OCTI was confirmed in 2073 of 6823 trachoma diagnosed children (30.4\%). Clinical trachoma prevalence was higher among females than males $(p<0.001)$, but gender comparison showed no statistical difference in the prevalence of OCTI $(p=0.077)$. Age and clinical trachoma $(r=-0.014$; $p<0.001)$ or OCTI $(r=-0.026 ; p=0.031)$ prevalence were negatively correlated. Clinical trachoma was different in different districts and counties $(p<0.001)$. Trachoma warrants close attention in Shanghai migrant children because the condition remains endemic in some schools.

\section{Introduction}

Trachoma is a well-known infectious eye disease caused by serotypes $\mathrm{A}, \mathrm{B}, \mathrm{Ba}$, and $\mathrm{C}$ of Chlamydia trachomatis. It is an endemic disease that shows an aggregated distribution in villages and communities within trachoma-prevalent areas throughout the world. Repeated infections lead to severe conjunctivitis, scarring of the eyelid, trichiasis, and corneal opacities that often result in visual impairment or blindness [1]. Trachoma was listed as second among five key preventable or treatable eye diseases by the World Health Organization (WHO) and was first in the infectious eye diseases category [2]. The WHO suggests implementing the SAFE strategy for eliminating blinding trachoma: surgery for trachomatous trichiasis, tetracycline, or azithromycin antibiotic treatment to clear ocular C. trachomatis infection (OCTI), facial cleanliness to reduce transmission of ocular C. trachomatis, and environmental improvement, particularly improved access to water and sanitation [2].
In mainland China, trachoma was previously widespread among the population with an average prevalence of 55\% and trachoma-induced corneal opacity was the most frequent cause of blindness until the 1980s [3]. National programs for the prevention of trachoma, improved socioeconomic development, and advanced basic sanitation meant that the prevalence of trachoma declined rapidly. As of 2006, the results of the National Sample Survey on Disabilities in China revealed that blinding trachoma had moved to a lower rank on the list of the causes of blindness $[4,5]$. However, the elimination of trachoma in any area of China has not been reported, and we suspect that trachoma remains endemic in some areas.

The epidemic condition of trachoma among the Shanghai migrant children, a rapidly expanding group, is of growing concern. In China internal migration is commonplace, as economic reforms have brought over 220 million migrants from villages to cities [6]. Most migrants travel from the western and central inlands, such as Anhui and Hunan, 
to the urban cities in the eastern coastal areas, such as Beijing and Shanghai [7]. In 2010, the number of migrants living in Shanghai reached 8.977 million, $38.21 \%$ of the total Shanghai resident population (23.475 million). Compared with the native Shanghai residents, the majority of these migrant labourers have lower incomes and lower levels of education [7]. The longstanding social system in China that separates rural and urban Chinese precludes many migrants from acquiring full citizenship in urban areas. As a result the migrant children attend migrant schools where the quality of teaching and facilities may be lower than in the schools the children of local origin attend [7]. Most of these migrant labourers live in crowded spaces with poor sanitary conditions that significantly increase the risk of poor health and infectious diseases in their children $[8,9]$.

In response to the need to understand the trachoma problem in migrant school aged children this study was commissioned by Shanghai Municipal Health Bureau, the government sector which is in charge of Shanghai health services and medical care management. From 1 December 2010 we conducted a survey to investigate the prevalence of trachoma and the correlating factors, the prevalence of OCTI and blindness caused by trachoma among Shanghai migrant children, and the results are documented and discussed in the present report. This report is the first of its kind in Shanghai and will provide important information for prevention and treatment of trachoma in children. This study was sponsored by Shanghai Charity Foundation, which further provided free antibiotics to the trachoma children.

\section{Materials and Methods}

2.1. Setting and Participants. Shanghai occupies a central location along China's eastern coastline. At the end of 2011, there were 17 administrative districts and counties in Shanghai. Approximately 10 to 20 residential communities or towns fall under the jurisdiction of each district or county. According to the data provided by the Shanghai Municipal Education Commission in 2010 (http://www.stats-sh.gov.cn/), a total of 154,265 children aged 6 to 16 years, most of whom are of the Han race, were studying in 206 migrant children schools (schools for children of rural-to-urban migration) near their parents' homes in Shanghai. These schools were located in nine administrative districts and one administrative county: Putuo, Minhang, Baoshan, Jiading, Jinshan, Songjiang, Qingpu, Fengxian, and Pudong Districts and Chongming County.

2.2. Study Design. This cross-sectional population-based survey was carried out between 1 December 2010 and 1 December 2012. The study personnel included 6 trained ophthalmologists and two experienced technicians from the Shanghai Eye Disease Prevention \& Treatment Centre and 30 general practitioners from various districts in Shanghai. School officials, teachers, and students and their parents (guardians) were informed of the purpose and procedures of this survey 1 week before it was conducted.
The field survey was conducted in the appropriate areas for each school. The general practitioners investigated the toilet facilities and the availability of clean water (tap water) for the children to wash their hands and faces. The facial hygiene of each child was examined, and the practitioners collected birthdates, birthplace, previous eye disease diagnoses, and treatment history data from the schools. During the investigation, the general practitioners also watched the children's faces, and a "clean face" was defined as a face free of flies and ocular or nasal discharge [10]. The ophthalmologists conducted eye examinations. The distance visual acuity with the subject's usual visual correction, if any (here referred to as the presenting distance visual acuity) [11], was firstly measured using a Snellen E chart. If the presenting distance visual acuity was lower than 20/400 (defined as blindness) [11], the main cause of blindness was subsequently identified. All of the children were then given a basic eye surface examination consisting of an examination of the eyelid and cornea with a handheld slit-lamp biomicroscope at $2.5 \mathrm{x}$ magnification. The eyes were examined for the presence of trichiasis or corneal opacity, which was followed by eversion of the upper lid and inspection of any follicles, infiltrations, or scars in the conjunctiva. Trachoma was clinically diagnosed and assessed in accordance with the simplified classification for trachoma proposed by WHO in 1987, as follows [12]: trachomatous inflammation-follicular (TF) was defined by the presence of 5 or more follicles (diameter $>0.5 \mathrm{~mm}$ ) in the central part of the upper tarsal conjunctiva. Trachomatous inflammation-intense (TI) was defined by pronounced inflammatory thickening of the upper tarsal conjunctiva with more than half of the normal deep tarsal vessels obscured; trachomatous scarring (TS) was defined by the presence of scarring in the tarsal conjunctiva accompanied by white lines or bands. Trachomatous trichiasis (TT) was defined by at least 1 eyelash rubbing on the eyeball or evidence of recent removal of in-turned eyelashes. Corneal opacity (CO) was defined by easily visible corneal opacity over the pupil in which the dense nature of the opacity obscured at least part of the pupil margin when viewed through the opacity or opacity resulting in significant visual impairment (i.e., worse than $20 / 60$ vision).

Only children with a positive clinical trachoma evaluation, defined as any sign of trachoma according to the WHO simplified system [12], were then tested with a further latex immunochromatography test. A child was confirmed as an OCTI patient when both clinical and further latex immunochromatography tests were positive. Two experienced technicians collected conjunctival secretion samples from the eyes with positive clinical trachoma diagnoses by rolling sterile swabs over the conjunctiva at least 4 times. Then they conducted the latex immunochromatography test on the secretion samples with the $C$. trachomatis Rapid Test Device (ACON, Hangzhou, China) to detect C. trachomatis. Hurley and associates recently evaluated the performance of the ACON Chlamydia Rapid Test Device test (also used in the present study) compared with gold standard nucleic acid amplification testing, and they found that the sensitivity and specificity of the ACON were $43.8 \%$ and $98.3 \%$ in men and $66.7 \%$ and $91.3 \%$ in women, respectively, but this 
was in genital chlamydia, not ocular [13]. The ACON latex immunochromatography test was simple and inexpensive compared to a standard nucleic acid amplification test, and that is why we chose the ACON test for the present largescale population-based survey. However, the limitation of the ACON latex immunochromatography test was obvious: with the chance of a high proportion of false-negatives, this test should not be used in clinical settings.

2.3. Quality Control. Before the formal investigation began, two experts in clinical trachoma diagnosis and treatment (Haidong Zou and Jianfeng Zhu) trained all of the study personnel. The training included descriptions of the purpose of the survey, the methodology of the survey, and the criteria for clinical trachoma diagnosis and grading. Standardised images for clinical trachoma diagnosis were used for training. Posttraining evaluation of the diagnostic accuracy was also undertaken by examinations to diagnose actual cases and those based on pictures of cases. We performed a preliminary investigation in four migrant children schools before the formal survey to examine the consistency of the diagnostic results between the different ophthalmologists. Overall, there was a high consistency between the two experts $(\kappa=0.93)$ in terms of trachoma diagnosis (prevalence rate). All of the problems encountered during this fieldwork were discussed and resolved by all study personnel. The study personnel leader reviewed suspected or confirmed positive cases. Any unresolved disagreements between the two assessors were referred to the group leader (Haidong Zou) for arbitration.

2.4. Ethics Statement. Because many of the migrant labourers work and live at building sites or bazaars and their children are placed in migrant children schools, it was difficult to obtain signed written consent from all of the parents during our investigation. With help from the school officials and teachers, oral informed consent to participate in this study was obtained from all the guardians (mostly by phone) and documented by the teachers. This research (including oral consent) was conducted according to the tenets of the Declaration of Helsinki and was approved by the Institutional Review Board at the Shanghai General Hospital, Shanghai Jiao Tong University.

2.5. Data Processing and Analysis. Experienced ophthalmic epidemiologists audited the completeness and logic of the data. The survey results were inputted, verified, and archived using the EpiData 3.0 program (The EpiData Association, Odense, Denmark). The statistical analyses were performed with the SPSS 16.0 software package (SPSS Inc., Chicago, IL, USA). Independent sample $t$-test was used to compare the age distributions across gender. Chi-square was used to compare the differences in the prevalence of clinical trachoma or OCTI among gender or different district and county distributions. Linear correlation was used to compare the differences in the prevalence of clinical trachoma or OCTI among age groups. $p$ values $<0.05$ were considered statistically significant.
TABle 1: Prevalence of different clinical trachoma classifications in 153,977 migrant school aged students in Shanghai by gender.

\begin{tabular}{lccc}
\hline $\begin{array}{l}\text { Trachoma } \\
\text { classification } \\
(\%)\end{array}$ & $\begin{array}{c}\text { Total } \\
n=153977\end{array}$ & $\begin{array}{c}\text { Male } \\
n=89660\end{array}$ & $\begin{array}{c}\text { Female } \\
n=64317\end{array}$ \\
\hline TF & 7878 & 4238 & 3640 \\
TI & 69 & 37 & 32 \\
TS & 78 & 46 & 32 \\
TT & 1 & 0 & 1 \\
CO & 3 & 2 & 1 \\
\hline Total & $8029(5.2)$ & $4323(4.8)$ & $3706(5.8)$ \\
\hline
\end{tabular}

Note. ${ }^{\#}$ Trachoma classification according to WHO 1987. TF: trachomatous inflammation-follicular; TI: trachomatous inflammation-intense; TS: trachomatous scarring; TT: trachomatous trichiasis; CO: corneal opacity.

\section{Results}

In all of 206 migrant children schools, there were at least two toilets available 24 hours and there was sufficient clean water (tap water) free-of-charge for the children to wash their hands and faces. A total of 153,977 students aged 6 to 16 years underwent interviews and eye examinations, which corresponds to a response rate of $99.8 \%(153,977 / 154,265)$. Of the participating students, 89,660 were male (58.2\%), and $64,317$ were female $(41.8 \%)$ (Table 1$)$. The average age of the students was 9.39 years with a standard deviation (SD) of 2.00 years. The average age of the male and female students was 9.39 years (SD: 1.99 years) and 9.38 years (SD: 2.01 years), respectively. The age distributions did not differ by gender $(t=1.15 ; p=0.25)$. More than $99 \%$ of the children had clean faces at the time of the investigation. Presenting distance visual acuities worse than 20/400 were found in eight eyes from seven students. Six eyes were blind from congenital cataracts and two had macular dystrophy; none of the blindness cases was caused by trachoma.

\subsection{Prevalence of and the Factors Correlated with Clinical} Trachoma. Trachoma was clinically diagnosed in 8,029 cases, which yielded a prevalence of $5.2 \%$. The total, male, and female patient numbers and prevalence rates of the different clinical trachoma classifications according to the WHO 1987 classification are shown in Table 1 . The total, male, and female patient numbers and prevalence rates of clinical trachoma in the different age groups are shown in Table 2. The prevalence of clinical trachoma was higher among females than males $\left(\chi^{2}=66.9 ; p<0.001\right)$. Negative linear correlations existed between age and the prevalence of clinical trachoma $(r=$ $-0.014 ; p<0.001)$.

The 206 migrant children schools were geographically located in 10 districts. In each district, the prevalence of clinical trachoma among local migrant children was estimated as $1.3 \%$ to $8.7 \%$. The number of migrant children schools and prevalence of clinical trachoma in different district and county distributions are shown in Table 3 . In 6 schools $(2.9 \%$, $6 / 206)$, no students with clinical trachoma were confirmed. In 24 schools $(11.7 \%, 24 / 206)$, the prevalence of clinical 
TABLE 2: Age and gender distributions of clinical trachoma in the 153,977 migrant school aged students in Shanghai.

\begin{tabular}{|c|c|c|c|c|c|c|}
\hline \multirow[b]{2}{*}{ Age (year) } & \multicolumn{2}{|c|}{ Male students } & \multicolumn{2}{|c|}{ Female students } & \multicolumn{2}{|c|}{ Total students } \\
\hline & $\begin{array}{c}\text { Total } \\
\text { number }\end{array}$ & $\begin{array}{l}\text { Children with } \\
\text { trachoma, } n(\%)\end{array}$ & $\begin{array}{c}\text { Total } \\
\text { number }\end{array}$ & $\begin{array}{l}\text { Children with } \\
\text { trachoma, } n(\%)\end{array}$ & $\begin{array}{c}\text { Total } \\
\text { number }\end{array}$ & $\begin{array}{c}\text { Children with } \\
\text { trachoma, } n(\%)\end{array}$ \\
\hline 6 & 3194 & $168(5.3)$ & 2407 & $146(6.1)$ & 5601 & $314(5.6)$ \\
\hline 7 & 13648 & $706(5.2)$ & 9813 & $568(5.8)$ & 23461 & $1274(5.4)$ \\
\hline 8 & 17746 & $839(4.7)$ & 12861 & $750(5.8)$ & 30607 & $1589(5.2)$ \\
\hline 9 & 14664 & $739(5.0)$ & 10559 & $637(6.0)$ & 25223 & $1376(5.5)$ \\
\hline 10 & 14137 & $715(5.0)$ & 10146 & $625(6.2)$ & 24283 & $1340(5.5)$ \\
\hline 11 & 12831 & $551(4.3)$ & 9079 & $530(5.8)$ & 21910 & $1081(5.0)$ \\
\hline 12 & 7846 & $386(5.0)$ & 5314 & $297(5.6)$ & 13160 & $683(5.2)$ \\
\hline 13 & 2997 & $111(3.7)$ & 2025 & $102(5.0)$ & 5022 & $213(4.2)$ \\
\hline 14 & 1395 & $54(3.9)$ & 1095 & $25(2.3)$ & 2490 & $79(3.2)$ \\
\hline 15 & 796 & $34(4.3)$ & 683 & $20(2.9)$ & 1479 & $54(3.7)$ \\
\hline 16 & 406 & $20(5.0)$ & 335 & $6(1.8)$ & 741 & $26(3.5)$ \\
\hline Total & 89660 & $4324(4.8)$ & 64317 & $3706(5.8)$ & 153977 & $8029(5.2)$ \\
\hline
\end{tabular}

TABLE 3: Different district and county distributions of clinical trachoma in the 153,977 migrant school aged children in Shanghai.

\begin{tabular}{|c|c|c|c|c|c|c|c|}
\hline $\begin{array}{l}\text { District or county } \\
\text { name }\end{array}$ & $\begin{array}{c}\text { Population of } \\
\text { children in migrant } \\
\text { school }\end{array}$ & $\begin{array}{l}\text { Children with } \\
\text { trachoma, } n(\%)\end{array}$ & $\begin{array}{l}\text { Number of migrant } \\
\text { children schools }\end{array}$ & $0 \%-1 \%$ & $>1 \%-5 \%$ & $>5 \%-10 \%$ & $>10 \%$ \\
\hline Pudong & 36563 & $2314(6.3)$ & 59 & 7 & 19 & 23 & 10 \\
\hline Fengxian & 12623 & $395(3.1)$ & 16 & 2 & 11 & 3 & 0 \\
\hline Jiading & 16374 & $449(2.7)$ & 19 & 2 & 15 & 1 & 1 \\
\hline Songjiang & 20346 & $1118(5.5)$ & 20 & 9 & 5 & 4 & 2 \\
\hline Jinshan & 4732 & $63(1.3)$ & 11 & 7 & 4 & 0 & 0 \\
\hline Putuo & 1826 & $137(7.5)$ & 3 & 0 & 1 & 1 & 1 \\
\hline Baoshan & 25057 & $1244(5.0)$ & 27 & 2 & 15 & 7 & 3 \\
\hline Minhang & 20305 & $1156(5.7)$ & 25 & 0 & 10 & 13 & 2 \\
\hline Chongming & 1470 & $128(8.7)$ & 2 & 0 & 1 & 0 & 1 \\
\hline Qingpu & 14681 & $1025(7.0)$ & 24 & 1 & 8 & 10 & 5 \\
\hline Total & 153977 & $8029(5.2)$ & 206 & 30 & 89 & 62 & 25 \\
\hline
\end{tabular}

trachoma was between $0 \%$ and $1 \%$. In 89 schools $(43.2 \%$, $89 / 206$ ), the prevalence of clinical trachoma was between $1 \%$ and $5 \%$. In 7 schools $(3.4 \%, 7 / 206)$, the prevalence of clinical trachoma was more than $15 \%$. The schools with the highest prevalence of clinical trachoma among the local migrant children were shown in Figure 1. Further analysis revealed a significant relationship between the district and county distributions and the prevalence of clinical trachoma among local migrant children $\left(\chi^{2}=714.0 ; p<0.001\right)$.

3.2. Prevalence of and the Factors Correlated with Immunologically Confirmed OCTI. Among the 8,029 clinical trachoma cases, conjunctival secretion samples were collected from $6,823(85.0 \%)$ students, including 3,642 males and 3,181 females. The other 1,206 students failed to cooperate with the sample collection because they were unable to tolerate the sterile swabs rolling over the conjunctiva. The latex immunochromatography tests revealed that 2,073 (30.4\%) of the 6,823 students were $C$. trachomatis positive. Bilateral infections occurred in 1,602 students and monocular infections occurred in 471 students. The total, male, and female patient numbers and prevalence of OCTI in the different age groups are shown in Table 4 . The prevalence of OCTI was higher among females than males, but there was not statistical difference $\left(\chi^{2}=3.131 ; p=0.077\right)$. Negative linear correlations existed between age and the prevalence of OCTI $(r=-0.026 ; p=0.031)$.

The number of migrant children schools and prevalence rates of OCTI in different district and county distributions are shown in Table 5. In each district, the prevalence rate of OCTI among local migrant children was a majority of greater than $10 \%$ (Table 5). Further analysis revealed a statistically significant difference with district and county distributions and the prevalence of OCTI among local migrant children $\left(\chi^{2}=165.3 ; p<0.001\right)$. 
TABLE 4: Age and gender distributions of ocular Chlamydia trachomatis infection in 6,823 migrant school aged students in Shanghai.

\begin{tabular}{|c|c|c|c|c|c|c|}
\hline \multirow[b]{2}{*}{ Age (year) } & \multicolumn{2}{|c|}{ Male students } & \multicolumn{2}{|c|}{ Female students } & \multicolumn{2}{|c|}{ Total students } \\
\hline & $\begin{array}{c}\text { Total } \\
\text { number }\end{array}$ & $\begin{array}{c}\text { Ocular } C . \\
\text { trachomatis } \\
\text { infection, } n(\%)\end{array}$ & $\begin{array}{c}\text { Total } \\
\text { number }\end{array}$ & $\begin{array}{c}\text { Ocular C. } \\
\text { trachomatis } \\
\text { infection, } n(\%)\end{array}$ & $\begin{array}{c}\text { Total } \\
\text { number }\end{array}$ & $\begin{array}{c}\text { Ocular } C . \\
\text { trachomatis } \\
\text { infection, } n(\%)\end{array}$ \\
\hline 6 & 130 & $35(26.9)$ & 111 & $39(35.1)$ & 241 & $74(30.7)$ \\
\hline 7 & 548 & $171(31.2)$ & 421 & $134(31.8)$ & 969 & $305(31.5)$ \\
\hline 8 & 691 & $208(30.1)$ & 661 & $224(33.9)$ & 1352 & $432(32)$ \\
\hline 9 & 631 & $185(29.3)$ & 542 & $168(31)$ & 1173 & $353(30.1)$ \\
\hline 10 & 622 & $191(30.7)$ & 550 & $171(31.1)$ & 1172 & $362(30.9)$ \\
\hline 11 & 486 & $142(29.2)$ & 475 & $140(29.5)$ & 961 & $282(29.3)$ \\
\hline 12 & 333 & $82(24.6)$ & 279 & $84(30.1)$ & 612 & $166(27.1)$ \\
\hline 13 & 91 & $32(35.2)$ & 87 & $28(32.2)$ & 178 & $60(33.7)$ \\
\hline 14 & 54 & $14(25.9)$ & 32 & $6(18.8)$ & 86 & $20(23.3)$ \\
\hline 15 & 34 & $8(23.5)$ & 18 & $5(27.8)$ & 52 & $13(25)$ \\
\hline 16 & 22 & $5(22.7)$ & 5 & $1(20)$ & 27 & $6(22.2)$ \\
\hline Total & 3642 & $1073(29.5)$ & 3181 & $1000(31.4)$ & 6823 & $2073(30.4)$ \\
\hline
\end{tabular}

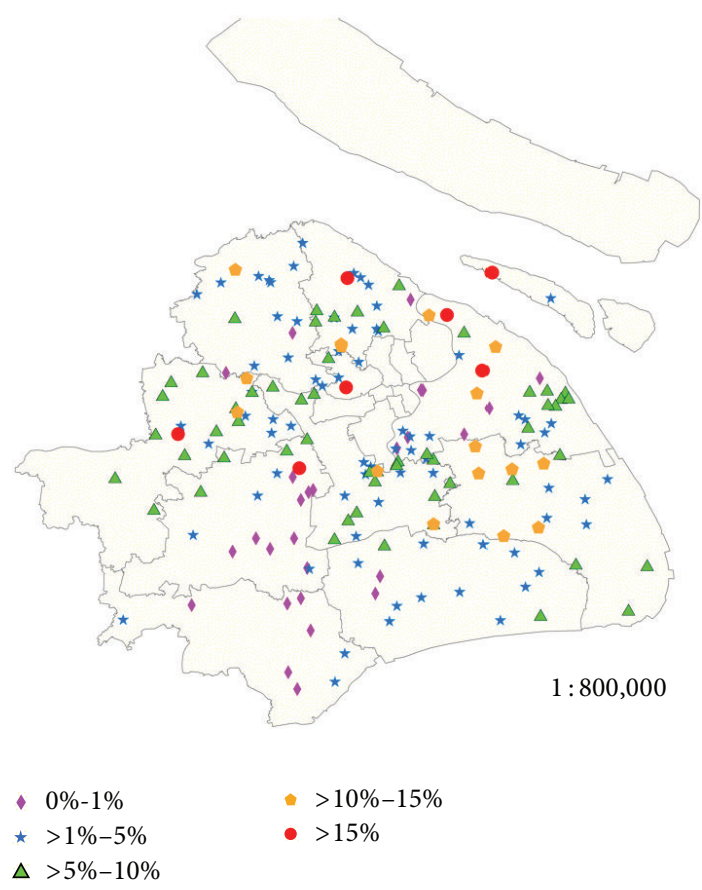

FIGURE 1: Geographical distribution of each individual migrant school with different prevalence of clinical trachoma in Shanghai. Symbols represent the prevalence according to the map key.

\section{Discussion}

The prevalence of trachoma in children can represent the burden of trachoma in a specific area [14]. As any child under 16 should receive 9 years of compulsory education in China, in Shanghai, a vast majority of the migrant labourers' children receive education free-of-charge in the nearby migrant children schools. Because our previous report found no cases of blindness caused by trachoma in children of local origin more than 6 years old in Shanghai [15], a positive conclusion can be drawn that there is no blindness caused by trachoma in children aged 6-16 in Shanghai, regardless of whether they are native or migrant. It is very likely that blindness from trachoma mostly occurs much later in life after repeated $C$. trachomatis infections [2].

Previous studies in China have only focused on the prevalence of clinical trachoma, which was much higher than in our study $[16,17]$. The differences might be attributable to the fact that the previous cluster sampling designed studies were conducted in relatively small samples of rural Chinese children. However, we found that trachoma is still endemic in some migrant children schools, which implies that trachoma warrants close attention in Shanghai because these infected children and their close contacts face a high risk of repeated infections.

To further realize the public health risks of C. trachomatis infection in Shanghai, we investigated the prevalence of OCTI confirmed immunologically in the migrant children in school. To the best of our knowledge, this is the first report of a large-scale population-based prevalence rate of OCTI in Chinese children. We think that the latex immunochromatography test positive rate (30.4\%) was likely to be because trachomatous follicles persist for long periods of time even when the infection has vanished, and latex immunochromatography requires a high antigen content, so false-negative diagnoses might have occurred in patients with subtle C. trachomatis infections.

Trachoma is a global problem [18]. Frequently reported risk factors that may be related to the prevalence of active trachoma include poor living conditions, heavy wind and dust, dirty water or no water, and elevated fly (Musca sorbens) densities [16, 17, 19-22]. We found no significant correlation between any of these factors and the prevalence of clinical trachoma or OCTI that was confirmed immunologically. The schools observed provided sufficient clean water to help the children maintain clean faces and hands. Future 
TABLE 5: Different district and county distributions of ocular C. trachomatis infection in 6,823 migrant school aged students in Shanghai.

\begin{tabular}{|c|c|c|c|c|}
\hline \multirow[t]{2}{*}{ District or county name } & \multirow[t]{2}{*}{$\begin{array}{c}\text { Ocular C. trachomatis infection, } \\
n(\%)\end{array}$} & \multirow[t]{2}{*}{$\begin{array}{l}\text { Number of migrant children } \\
\text { schools }\end{array}$} & \multicolumn{2}{|c|}{$\begin{array}{c}\text { Number of schools with different prevalence } \\
\text { of ocular C. trachomatis infection confirmed } \\
\text { immunologically }\end{array}$} \\
\hline & & & $<10 \%$ & $\geq 10 \%$ \\
\hline Pudong & $632(28.8)$ & 59 & 9 & 50 \\
\hline Fengxian & $177(49.0)$ & 16 & 0 & 16 \\
\hline Jiading & $153(35.7)$ & 19 & 0 & 19 \\
\hline Songjiang & $192(41.0)$ & 20 & 12 & 8 \\
\hline Jinshan & $12(41.4)$ & 11 & 8 & 3 \\
\hline Putuo & $29(22.7)$ & 3 & 0 & 3 \\
\hline Baoshan & $201(19.6)$ & 27 & 5 & 22 \\
\hline Minhang & $300(27.8)$ & 25 & 1 & 24 \\
\hline Chongming & $38(30.9)$ & 2 & 2 & 0 \\
\hline Qingpu & $339(34.3)$ & 24 & 1 & 23 \\
\hline Sum & $2073(30.4)$ & 206 & 38 & 168 \\
\hline
\end{tabular}

close observations of the living conditions, physical fitness, hygiene habits, and susceptibility to C. trachomatis infections might help elucidate the exact risk factors of OCTI in Shanghai migrant school children. The prevalence in this study was $30.4 \%$ in these migrant school aged children. WHO guidelines are that a prevalence of TF of $\geq 5 \%$ in $1-9$-yearold children indicates that active trachoma is a public health problem, and in such areas the A, F, and E components of the SAFE strategy should be implemented including mass drug administration of the antibiotic azithromycin [12]. In many other countries worldwide the prevalence in some areas reaches more than $10 \%$ including many countries in Africa [23-31]. Even in a developed country such as Australia, some indigenous populations in remote areas have a prevalence of trachoma above WHO's elimination threshold [32].

Most studies find no gender differences in prevalence of active trachoma $[20,33]$. But the prevalence of trachoma was previously found to be much higher in girls than in boys in China [17], which is consistent with our study results, and has also been shown in Cameroon [28]. However, in contrast a study in Guinea Bissau found that being female was associated with reduced odds of active trachoma, but not infection [34]. The authors of the Chinese study suggested that, in rural Chinese areas, male children experience better living conditions than female children due to the traditional preference for males and this is found in other communities $[17,35]$. It has also been suggested that female children may be at greater risk for active trachoma because of their role in taking care of younger children in the family [20]. Like previous studies $[36,37]$, the present study observed a significant difference of the prevalence of trachoma with age. Older children and adolescents have greater understanding of human health and better hygiene habits, and we hypothesize that these might lead to decreases in the prevalence of trachoma. In addition, the duration of episodes of active disease and infection decrease with increasing age [38-40].

There are inherent weaknesses of this study. Trachoma is supposed to be more common among preschool children than older children. However, we found it almost impossible to conduct a survey of preschool migrant children in Shanghai. Most of the preschool migrant children live with their parents in tens of thousands of workplaces with no exact demographic data. In some cases, the preschool children live with grandparents who do not live in Shanghai because of the difficulty involved in looking after them while the parents work. Infants also cannot cooperate with the eye examination and conjunctival secretion sample collection. An African study suggested that school surveys might underestimate the prevalence because differences were found between those who attended school and those who did not; however, in Nigeria where school attendance is high the differences were not seen $[38,39]$. As the rate of school attendance is high in the Shanghai migrant school aged children the prevalence in our study may be fairly accurate. Because it was impossible to collect conjunctival secretion samples from all 153,977 students, we only collected samples from those with distinct clinical features, and a tiny group of children with immediate early infection and no signs of trachomatous follicles might have been omitted. Some students would not cooperate with having a swab. We presumed that $30.4 \%$ of the uncooperative 1206 students were also likely to be positive as this was the rate in those who could be swabbed; then a total of 2439 cases of the 8029 clinical trachoma students would be OCTI positive, and in that situation the estimated OCTI prevalence would be $1.6 \%$. Furthermore, as reported by Hurley and associates, although the latex immunochromatography kit used in the present study has high specificity between $33.3 \%$ and $57.2 \%$ of true OCTI infected cases will not be positive compared to the rates by gold standard nucleic acid amplification tests [13]. Accurate detection of serotypes A, $\mathrm{B}, \mathrm{Ba}$, and $\mathrm{C}$ C. trachomatis requires a more dedicated latex immunochromatography kit or a combination of the current kit with a highly sensitive nucleic acid amplification based detection method; this might be possible in future studies. We also did not collect information from children of local origin in nonmigrant schools as there are no recent data 
on the prevalence of trachoma in native Shanghai children; this would have provided important information and enabled comparisons with the rates in the native population.

\section{Conclusion}

The prevalence of clinical trachoma was $5.2 \%$ and the infection was somewhat prevalent (prevalence close to or higher than $5 \%$ in some migrant schools). Given its large population, China has a large number of children who are currently living in environments similar to, or worse than, those of the migrant school children in Shanghai. This indicates that trachoma should still be regarded as an issue of concern in China. Mainly based on the present study results, on March 5, 2013, Shanghai Municipal Health Bureau issued a project plan in order to eliminate blinding trachoma and to reduce the active trachoma in Shanghai before 2016, which is in line with the Chinese national program.

\section{Competing Interests}

The authors declare that there is no conflict of interests regarding the publication of this paper.

\section{Authors' Contributions}

Wenwen Xue and Lina Lu contributed equally to this paper.

\section{Acknowledgments}

The authors thank all the eye diseases prevention workers who participated in this study. They are from Huangpu, Xuhui, Changning, Jing'an, Putuo, Zhabei, Hongkou, Yangpu, Minhang, Baoshan, Jiading, Jinshan, Songjiang, Qingpu, Fengxian, and Pudong Administrative Districts and Chongming Administrative County. The study participants and their families were all acknowledged for their contribution. This study was supported by the Three-Year Action Program of Shanghai Municipality for Strengthening the Construction of the Public Health System (2011-2013) (Grant no. 201115) and Shanghai New Hundred Talents Program from Shanghai Medical and Family Planning Committee (Project no. XBR2013109).

\section{References}

[1] S. Resnikoff, D. Pascolini, D. Etya'ale et al., "Global data on visual impairment in the year 2002," Bulletin of the World Health Organization, vol. 82, no. 11, pp. 844-851, 2004.

[2] "WHO alliance for the global elimination of blinding trachoma by the year 2020. Progress report on elimination of trachoma, 2013," Weekly Epidemiological Record, vol. 89, no. 39, pp. 421428, 2014.

[3] C. Hu, "An epidemiologic survey of trachoma in Shunyi County, Beijing," Zhonghua Yan Ke Za Zhi, vol. 25, no. 3, pp. 175-178, 1989.

[4] H.-J. Guan, "Present status and development of prevention of blindness and ophthalmic epidemiologic studies in China,"
Chinese Journal of Ophthalmology, vol. 46, no. 10, pp. 938-943, 2010.

[5] H. Chen, X. Wu, M. Wei et al., "Changes in the prevalence of visual impairment due to blinding trachoma in Sichuan province, China: a comparative study between 1987 and 2006," Ophthalmic Epidemiology, vol. 19, no. 1, pp. 29-37, 2012.

[6] Y. Lu and H. Zhou, "Academic achievement and loneliness of migrant children in China: school segregation and segmented assimilation," Comparative Education Review, vol. 57, no. 1, pp. 85-116, 2013.

[7] D. F. K. Wong, Y. Chang, X. He, and Q. Wu, “The protective functions of relationships, social support and self-esteem in the life satisfaction of children of migrant workers in Shanghai, China," The International Journal of Social Psychiatry, vol. 56, no. 2, pp. 143-157, 2010.

[8] S. Hu, H. Tan, A. Peng et al., "Disparity of anemia prevalence and associated factors among rural to urban migrant and the local children under two years old: a population based crosssectional study in Pinghu, China," BMC Public Health, vol. 14, article 601, 2014.

[9] K. Han, H. Zheng, Z. Huang et al., "Vaccination coverage and its determinants among migrant children in Guangdong, China," BMC Public Health, vol. 14, article 203, 2014.

[10] S. West, B. Muñoz, M. Lynch et al., "Impact of face-washing on trachoma in Kongwa, Tanzania," The Lancet, vol. 345, no. 8943, pp. 155-158, 1995.

[11] J. Zhao, L. B. Ellwein, H. Cui et al., "Prevalence of vision impairment in older adults in rural China. The China NineProvince Survey," Ophthalmology, vol. 117, no. 3, pp. 409-416, 2010.

[12] B. Thylefors, C. R. Dawson, B. R. Jones, S. K. West, and H. R. Taylor, "A simple system for the assessment of trachoma and its complications," Bulletin of the World Health Organization, vol. 65, no. 4, pp. 477-483, 1987.

[13] D. S. Hurly, M. Buhrer-Skinner, S. G. Badman et al., "Field evaluation of the CRT and ACON chlamydia point-of-care tests in a tropical, low-resource setting," Sexually Transmitted Infections, vol. 90, no. 3, pp. 179-184, 2014.

[14] H. Faal, D. Minassian, S. Sowa, and A. Foster, "National survey of blindness and low vision in the Gambia: results," British Journal of Ophthalmology, vol. 73, no. 2, pp. 82-87, 1989.

[15] J.-F. Zhu, H.-D. Zou, X.-G. He et al., "Cross-sectional investigation of visual impairing diseases in Shanghai blind children school," Chinese Medical Journal, vol. 125, no. 20, pp. 3654-3659, 2012.

[16] L.-H. Wang, B. Wang, H.-Y. Wang et al., "Prevalence of trachoma in rural primary school children in Tengzhou City of Shandong Province in China," Zhonghua Yan Ke Za Zhi, vol. 46, no. 5, pp. 395-399, 2010.

[17] Z. Ren, Q.-F. Liang, S. Guo, Y.-M. Zhou, R. Li, and X.-G. Sun, "Prevalence and risk factors for trachoma in primary school children in Datong City in China," Zhonghua Yan Ke Za Zhi, vol. 44, no. 6, pp. 507-510, 2008.

[18] A. Fenwick, "The global burden of neglected tropical diseases," Public Health, vol. 126, no. 3, pp. 233-236, 2012.

[19] S. Polack, H. Kuper, A. W. Solomon et al., "The relationship between prevalence of active trachoma, water availability and its use in a Tanzanian village," Transactions of the Royal Society of Tropical Medicine and Hygiene, vol. 100, no. 11, pp. 1075-1083, 2006. 
[20] I. Golovaty, L. Jones, B. Gelaye et al., "Access to water source, latrine facilities and other risk factors of active trachoma in Ankober, Ethiopia," PLoS ONE, vol. 4, no. 8, Article ID e6702, 2009.

[21] P. M. Emerson, R. L. Bailey, O. S. Mahdi, G. E. L. Walraven, and S. W. Lindsay, "Transmission ecology of the fly Musca sorbens, a putative vector of trachoma," Transactions of the Royal Society of Tropical Medicine and Hygiene, vol. 94, no. 1, pp. 28-32, 2000.

[22] S. K. West, P. Rapoza, B. Muñoz, S. Katala, and H. R. Taylor, "Epidemiology of ocular chlamydial infection in a trachomahyperendemic area," Journal of Infectious Diseases, vol. 163, no. 4, pp. 752-756, 1991.

[23] E. A. Cromwell, A. Amza, B. Kadri et al., "Trachoma prevalence in Niger: results of 31 district-level surveys," Transactions of the Royal Society of Tropical Medicine and Hygiene, vol. 108, no. 1, pp. 42-48, 2014.

[24] H. R. Taylor, S. S. Fox, J. Xie, R. A. Dunn, A.-L. M. R. Arnold, and J. E. Keeffe, "The prevalence of trachoma in Australia: the National Indigenous Eye Health Survey," Medical Journal of Australia, vol. 192, no. 5, pp. 248-253, 2010.

[25] K. Kalua, T. Chirwa, L. Kalilani, S. Abbenyi, M. Mukaka, and R. Bailey, "Prevalence and risk factors for trachoma in central and southern Malawi," PLoS ONE, vol. 5, no. 2, Article ID e9067, 2010.

[26] B. Noa Noatina, G. Kagmeni, Y. Souleymanou et al., "Prevalence of trachoma in the north region of Cameroon: results of a survey in 15 health districts," PLoS Neglected Tropical Diseases, vol. 8, no. 6, Article ID e2932, 2014.

[27] J. D. King, T. Teferi, E. A. Cromwell et al., "Prevalence of trachoma at sub-district level in ethiopia: determining when to stop mass azithromycin distribution," PLoS Neglected Tropical Diseases, vol. 8, no. 3, article e2732, 2014.

[28] B. Noa Noatina, G. Kagmeni, M. N. Mengouo et al., "Prevalence of trachoma in the Far North Region of Cameroon: results of a Survey in 27 Health Districts," PLoS Neglected Tropical Diseases, vol. 7, no. 5, Article ID e2240, 2013.

[29] T. Edwards, J. Smith, H. J. W. Sturrock et al., "Prevalence of Trachoma in Unity State, South Sudan: results from a large-scale population-based survey and potential implications for further surveys," PLoS Neglected Tropical Diseases, vol. 6, no. 4, article e1585, 2012.

[30] A. Hassan, J. M. Ngondi, J. D. King et al., "The prevalence of blinding trachoma in northern states of Sudan," PLoS Neglected Tropical Diseases, vol. 5, no. 5, Article ID e1027, 2011.

[31] A. Abdou, B. Nassirou, B. Kadri et al., "Prevalence and risk factors for trachoma and ocular Chlamydia trachomatis infection in Niger," British Journal of Ophthalmology, vol. 91, no. 1, pp. 1317, 2007.

[32] E. M. Harding-Esch, T. Edwards, H. Mkocha et al., "Trachoma prevalence and associated risk factors in the Gambia and Tanzania: baseline results of a cluster randomised controlled trial," PLoS Neglected Tropical Diseases, vol. 4, no. 11, article e861, 2010.

[33] E. M. Harding-Esch, T. Edwards, A. Sillah et al., "Risk factors for active trachoma in the Gambia," Transactions of the Royal Society of Tropical Medicine and Hygiene, vol. 102, no. 12, pp. 1255-1262, 2008.

[34] A. R. Last, S. E. Burr, H. A. Weiss et al., "Risk factors for active trachoma and ocular Chlamydia trachomatis infection in treatment-naive trachoma-hyperendemic communities of the Bijagós Archipelago, Guinea Bissau," PLoS Neglected Tropical Diseases, vol. 8, no. 6, Article ID e2900, 2014.
[35] A. G. Smith, A. T. Broman, W. Alemayehu, B. E. Munoz, S. K. West, and E. W. Gower, "Relationship between trachoma and chronic and acute malnutrition in children in rural Ethiopia," Journal of Tropical Pediatrics, vol. 53, no. 5, pp. 308-312, 2007.

[36] T. Edwards, E. M. Harding-Esch, G. Hailu et al., "Risk factors for active trachoma and Chlamydia trachomatis infection in rural Ethiopia after mass treatment with azithromycin," Tropical Medicine and International Health, vol. 13, no. 4, pp. 556-565, 2008.

[37] R. F. Baggaley, A. W. Solomon, H. Kuper et al., "Distance to water source and altitude in relation to active trachoma in Rombo district, Tanzania," Tropical Medicine and International Health, vol. 11, no. 2, pp. 220-227, 2006.

[38] R. Bailey, T. Duong, R. Carpenter, H. Whittle, and D. Mabey, "The duration of human ocular Chlamydia trachomatis infection is age dependent," Epidemiology and Infection, vol. 123, no. 3, pp. 479-486, 1999.

[39] J. D. King, P. Odermatt, J. R. Utzinger et al., “Trachoma among children in community surveys from four African Countries and implications of using school surveys for evaluating prevalence," International Health, vol. 5, no. 4, pp. 280-287, 2013.

[40] N. C. Grassly, M. E. Ward, S. Ferris, D. C. Mabey, and R. L. Bailey, "The natural history of trachoma infection and disease in a Gambian cohort with frequent follow-up," PLoS Neglected Tropical Diseases, vol. 2, no. 12, article e341, 2008. 


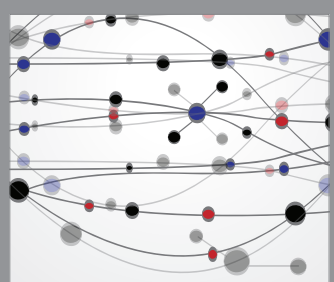

The Scientific World Journal
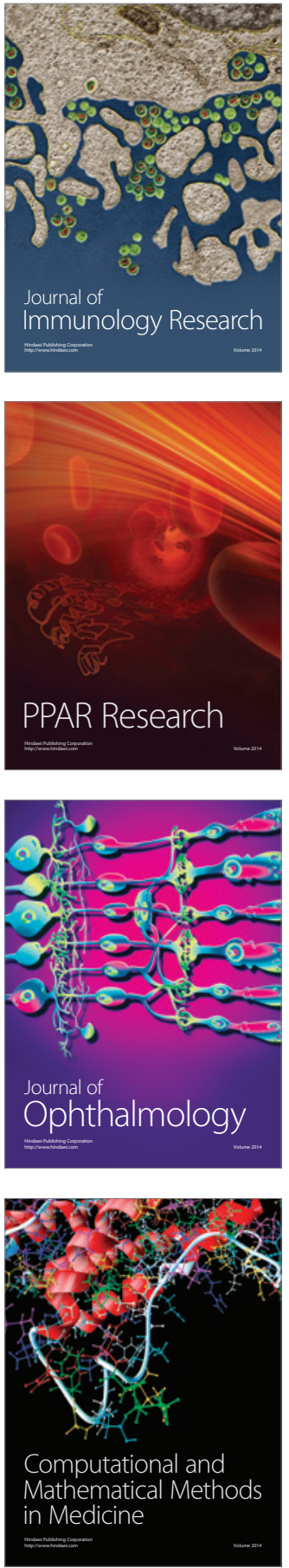

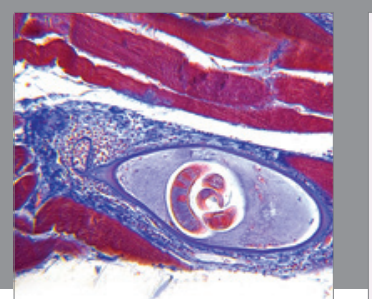

Gastroenterology Research and Practice

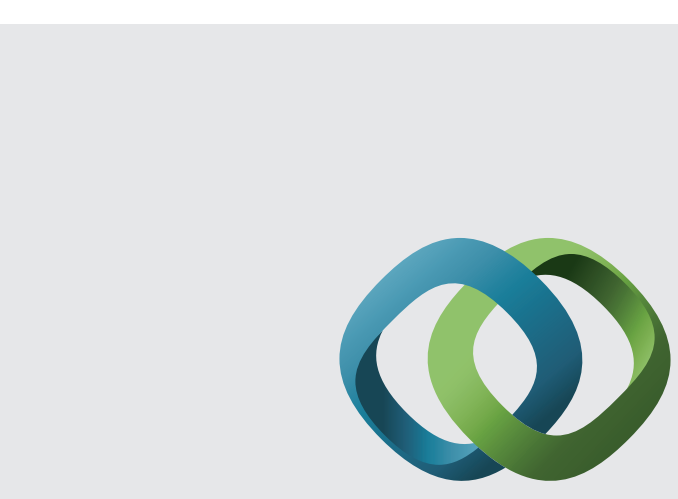

\section{Hindawi}

Submit your manuscripts at

http://www.hindawi.com
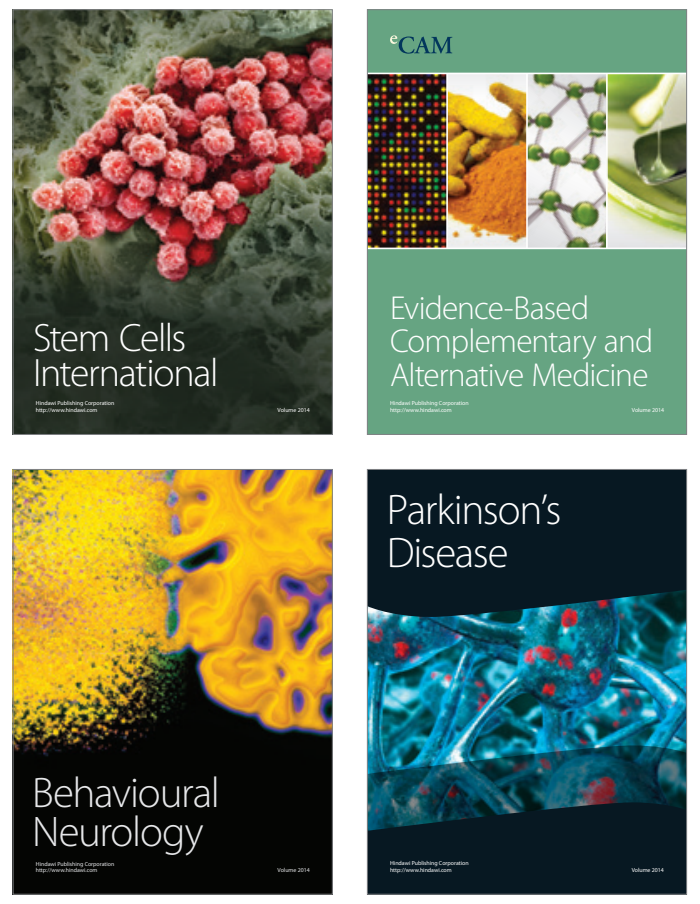
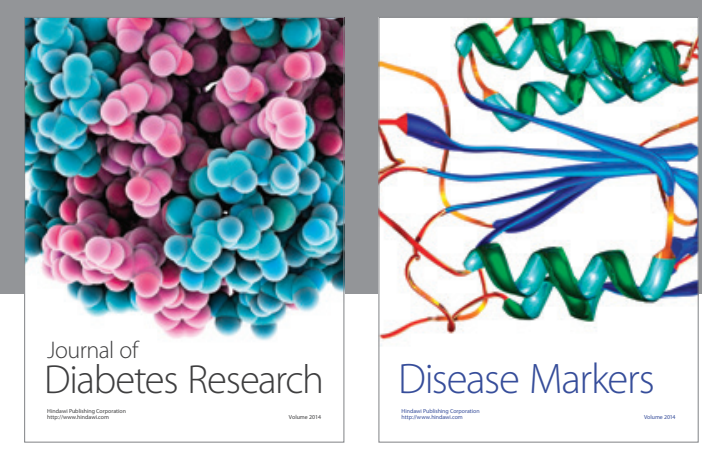

Disease Markers
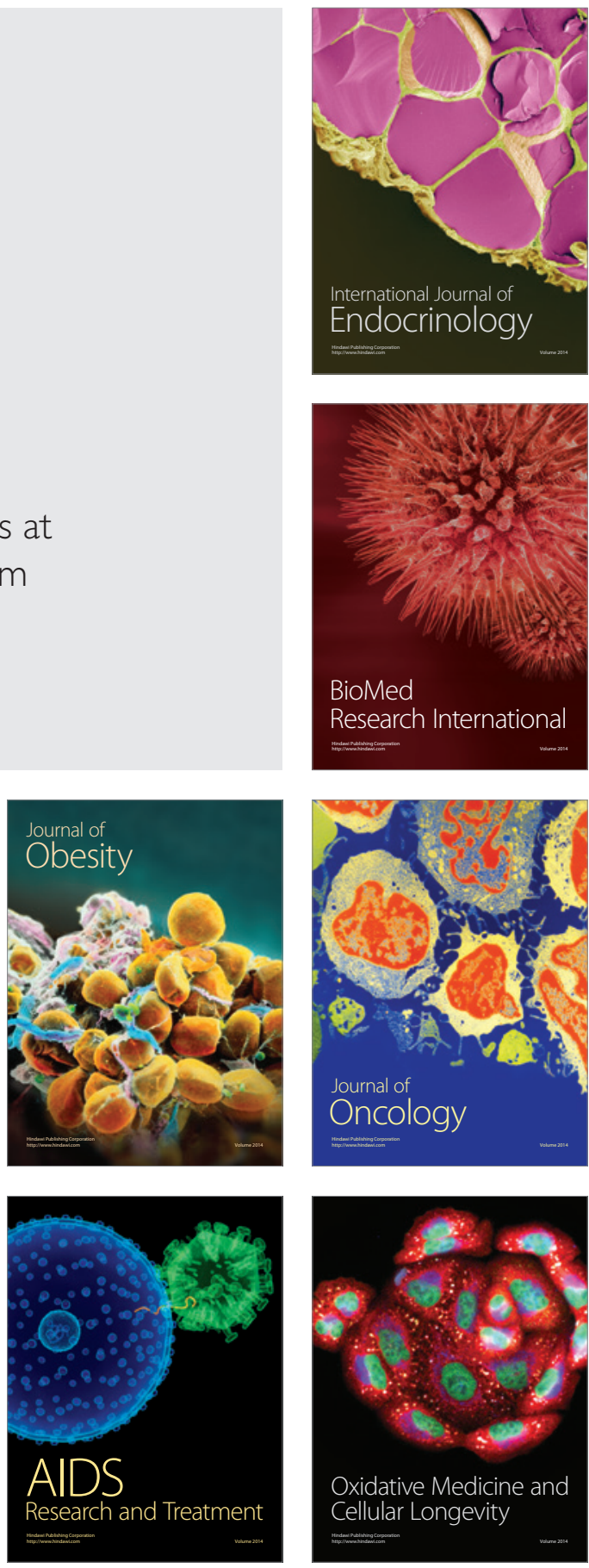